\title{
RESEARCH ON CHANGE OF TIME-HORNED APPAREL BRAND PERSONALITY AFTER DIFFERENT FIT EXTENSION
}

\author{
${ }^{1}$ Qiuyue Wang, ${ }^{2}$ Ping Zhao \\ ${ }^{1}$ School of Business, Beijing Institute of Fashion Technology, P.R. China \\ ${ }^{2}$ School of Fashion Art and Engineering, Beijing Institute of Fashion Technology, P.R. China \\ 1'sxywqy@bift.edu.cn, 2fzyzp@bift.edu.cn
}

Key words: Fit, Time-horned brand, Brand extension

\begin{abstract}
In the tide of economic globalization, brand extension has become essential to promote the development of enterprise strategy. In this paper, take an old-famous apparel brand in China as an example, to study the difference between the high and low fit extension influence the parent brand personality to the consumers' mind. In this paper, there are some following conclusions: firstly, whether high or low fit brand extension, the mother will be positive influence on stimulus dimensions of brand personality dimensions, rugged dimension; Negative influence sincere dimensions, capacity dimension, senior dimension; Secondly, a lower fit extension for parent brand personality will affect the magnitude of the above high fit.
\end{abstract}

\section{INTRODUCTION}

According to a survey, launching a new product will spend nearly one hundred million yen for establishing certain popularity in the market, sometimes the failure rate is $50 \%$, while developing a consumers' familiar brand to a new product has become the choice of many enterprises.

Based on a time-honored apparel brand as the object, this paper discusses the change of the evaluation of the parent brand personality with higher and lower fit of brand extension. This article conclusion will provide inspiration for parent brand personality maintenance after brand extension, and also give relevant reference for some time-horned garment enterprises development in the new era.

\section{LITERATURE REVIEW}

\section{Brand Extension}

Brand extends is refers to the enterprise will develop and extend the success of the parent brand to new products, which are nearly the same original product or the products even not in the same industry by relying on the existing successful brand. Brand extension strategy can help new products establish successful brand reputation rapidly, and save marketing costs' at the beginning. However, the brand extension is also likely to have a negative impact for the parent brand, such as the dilution of the original brand personality of the parent brand. Those unsuccessful extended product will not only hurt itself, also at the same time can make the bad impression to the parent brand, even weaken the parent brand core competitiveness.

Fit

Fit is the degree of extension that consumers accept a kind of new product as a brand that they are looking forward. The fit between the parent brand and extended product includes three aspects, product category and characteristics, interests and goals, as well as the brand personality and image.

\section{Brand Personality}

In 1955, scholars firstly present brand personality [1], since then Sirgy put forward the opinion that any brand or product should be with personality in 1982[2], professor Aaker used the Big Five theory model of personality to study the theoretical model of brand personality dimensions for exploratory research, which concluded that brand personality dimensions including Sincerity, Excitement, Competence, Sophistication and Ruggedness [3]. Up to now, more and more domestic 
and foreign scholars researched on brand personality. At present, most scholars agree with the conclusion that brand personality is one of the most important dimensions of brand image, which includes brand performance, brand personality and the company image as well, rather than the only dimension [4].

\section{Hypothesis}

H1: There are differences between the parent brand personality evaluation after high and low fit of brand extension;

H2: The evaluation of parent brand personality will be improved after higher fit of brand extension;

H3: The evaluation of parent brand personality will be diluted after lower fit of brand extension.

\section{METHODOLOGY}

\section{Method and Research Design}

Based on a time-horned apparel brand with a history of nearly 60 years, for example, this paper try to explore the changes of brand personality evaluation among original parent brand and evaluation after different fit of brand extension. Firstly, this paper respectively adapted the three material that described the parent brand original situation, new situation after high fit extension and low fit extension as the starting materials. Then, using the brand personality dimensions scale of professor Aaker, this paper measured after three materials conducted to the participants respectively. Finally, this paper compares the test results .The research model is shown in the Fig.1 below.
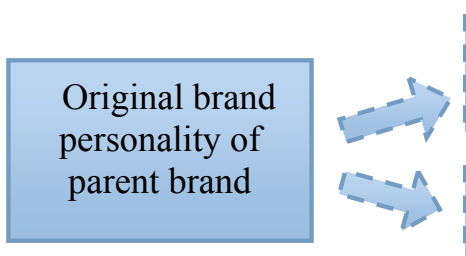

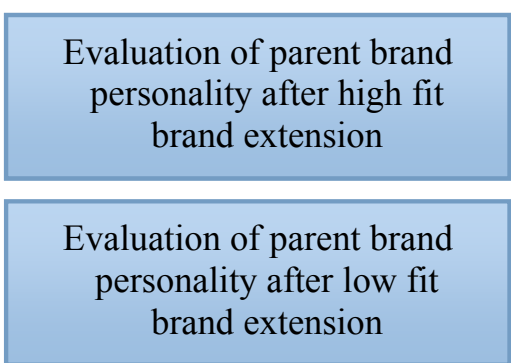

Fig.1 Research model

By reading and translating the related documents to modify the test material, the pre-test 40 juniors $(\mathrm{M}=20, \mathrm{~F}=20)$ writing the highest and lowest fit industries comparing to apparel industry in their minds, and combined with expert advices, this paper finally perfect the three prepare materials. This paper finds that bags and suitcases are the highest fitting products to apparel and the service of express delivery is the lowest fitting to apparel industry. Then, this paper selects 100 junior and senior students $(\mathrm{F}=50, \mathrm{M}=50)$ complete three brand personality tests respectively evaluating the original parent brand personality and those after different fit of brand extension.

Preparation of a formal questionnaire mainly includes three parts in this paper, parent brand present information, the material after parent brand extended to bags and suitcases industry and after parent brand extended to the service of express delivery.

\section{Measurement}

First of all, let the participants read about the parent brand present material, then according to Aaker (1997) of the five dimensions of brand personality scale, evaluate the parent brand initial brand personality. Before the beginning of the following tests, this paper tries to make respondents forget all before reading the following materials. Then, let the participants read about the material that the parent brand extended to bags and suitcases industry (a high fit brand extension assumption), and then let the participants complete the test of parent brand personality according to the situation for high fit extension. The next test is the same with the second step; let the participants complete the test of parent brand personality according to the situation for low fit extension. 


\section{Data Collection}

College students were invited to take part in this study. Selecting student respondents ensures a highly homogeneous respondent set. Prospective participants for the samples in the study were recruited from a college in Beijing. A total of 100 students participated in the study to earn extra credit points. After eliminating incomplete responses $(n=4)$ and respondents who exhibited extreme and consistent high or low rating patterns $(n=5)$, the final sample was reduced to 91 . The sample was comprised of approximately $41 \%$ males and 59\% females. Their average age was 20.2 years old. The participants' backgrounds consisted of students with $60 \%$ junior and $40 \%$ senior.

\section{DATA ANALYSES AND RESULTS}

Evaluations of the fit of brand extension, brand personality adopted Likert 7-scaled test, all data complete statistical analysis by using SPSS19.0. Data analyses and results are as following:

Table 1 Brand personality comparison with different fit extension

\begin{tabular}{c|c|c|c|c|c|c|c}
\hline \multirow{2}{*}{$\begin{array}{c}\text { Parent Brand } \\
\text { personality }\end{array}$} & \multicolumn{2}{|c|}{ Original } & \multicolumn{2}{c|}{$\begin{array}{c}\text { After high fit } \\
\text { extension }\end{array}$} & \multicolumn{2}{c|}{$\begin{array}{c}\text { After low fit } \\
\text { extension }\end{array}$} & \multirow{2}{*}{ Change } \\
\cline { 2 - 8 } & Mean & $\begin{array}{c}\text { Cronbach's } \\
\alpha\end{array}$ & Mean & $\begin{array}{c}\text { Cronbach's } \\
\alpha\end{array}$ & Mean & $\begin{array}{c}\text { Cronbach's } \\
\alpha\end{array}$ & \\
\hline Sincerity & 5.46 & 0.833 & 5.29 & 0.883 & 5.00 & 0.839 & decrease \\
\hline Excitement & 3.98 & 0.900 & 4.78 & 0.885 & 5.15 & 0.805 & increase \\
\hline Competence & 5.64 & 0.772 & 5.53 & 0.851 & 5.26 & 0.832 & decrease \\
\hline Sophistication & 5.17 & 0.717 & 4.95 & 0.714 & 4.65 & 0.748 & decrease \\
\hline Ruggedness & 5.4 & 0.727 & 5.42 & 0.854 & 5.50 & 0.823 & increase \\
\hline
\end{tabular}

The Cronbach's Alpha of different dimensions of three brand personality test (initial, after high and fit extension) are greater than 0.7 , so this paper take the mean score of each sub-dimension as the main dimension score.

\section{Original Evaluation}

According to the initial evaluation of parent brand personality, the results in Table 1 show that due to the selected parent brand is a time-horned apparel brand once provided service for government leaders and social elites in China, so the score of parent brand personality in sincere dimension is 5.46, competence is 5.64, and ruggedness is 5.40. However, maybe due to the same reasons, original parent brand personality in the dimension of excitement score is 3.98 , which is the lowest, this may be related to the public for the old brand impression focused on traditional, old-fashioned and other words, that old brand does not too big relations to the words such as novelty, innovation and so on.

\section{Evaluation After High Fit Extension}

After high fit brand extension, the scores of brand personality dimensions of Sincerity and Competence have declined slightly to 5.29 and 5.53. Some research once mentioned that higher fit of brand extension may dilute the parent brand's the most outstanding features, for this selected parent brand, the higher scores of original parent brand personality are the dimension of sincerity and competence, now they have been harmed [5].

However the results in Table1 show that the increase on the dimension of excitement(4.78)than the original evaluation(3.98), this may be because for an old brand, higher fit extension will give a person with dynamic image and development, so consumers will increase their understanding of the brand. The score of dimension sophistication is 4.96, which decreases from 5.17. This result shows a common important issue that some fixed high-end consumer types enterprise are facing is that some of the original brand characters related to upper class will be rapidly diluted after brand extension, because the original target consumers are worrying about the brand will extend to the mass market. The score of dimension ruggedness is 5.42, which is just slightly higher than the original evaluation(5.40), the literature also has mentioned that from consumer's point of view, the extension of higher fit for companies means 'easy' and 'didn't work hard enough', the extension of higher fit also means that companies will own the production and operation in an industry. 


\section{Evaluation After Lower Fit Extension}

After low fit extension, the parent brand personality in the dimension of sincerity decreased to 5.01.There is a Chinese old saying, an interlacing as foster, because of low fit extension, consumers may have such impression on parent brand as irrelevant, blind and pursuing interests in the short run, which leads to the score decrease on sincerity. For the dimension of excitement, the score is 5.15 , which has greatly increased compared with the initial evaluation before low fit extension. The reason may due to the activity of extending to low fit industry give consumer strong impact for an old brand and help them develop new perception of this brand [6]. For the dimension of competence, the score reduced to 5.26, which showed that consumers may have some concerns about the ability of parent brand to balance two unrelated industry. The score of dimension sophistication after low fit extension decreased significantly to 4.66. After the low fit extension, the most obvious characteristic is diluted also. The score of dimension ruggedness increased to 5.51.For low fit extension, consumers will have such association with the brand like tough and brave, so the dimension scores increased.

\section{CONCLUSIONS AND IMPLICATION}

Higher or lower fit extension will influence the evaluation of parent brand personality. In the dimensions of excitement and ruggedness, the scores of evaluation of brand personality show the positive influence on parent brand personality. While in the dimensions of sincerity, competence and sophistication, the scores show the negative influence on parent brand personality. H1 is confirmed. In excitement and ruggedness two dimensions, low fit extension let consumers think positive influence of brand personality and the scores in these two dimensions are higher than the initial and high fit extension evaluation. In sincerity, competence and sophistication dimensions, consumers consider brand extension will dilute parent brand personality. The scores of low fit extension in all three dimensions are lower than the initial and high fit extension evaluation. H2 and H 3 partially confirmed.

\section{LIMITATIONS AND FUTURE STUDIES}

College students as subjects restrict external validity of the results of the study, the future research will be try to extend the scope of the investigation to brand target customers, to expand the research conclusions and extend external validity of the study. In addition, this study focuses on the different fit extension influences to the parent brand personality, future research can also be aimed at repairing method to parent brand personality after brand dilution.

\section{Acknowledgements}

This work was financially supported by BIFT Special Requirements for The Project of Rescue Inheritance and Design Innovation of Chinese Traditional Costume Culture (XKJY02150201), Young Talent Program of Beijing Education Commission (YETP1404), and BIFT Education Foundation (2013A-12).

\section{References}

[1] Gardner, B., \& Levy, J. The Product and Brand. Harvard Business Review, 1955, 3(4), p33-39.

[2] Sirgy, J. L. Self-concept in consumer behavior: a critical review. Journal of Consumer Research. 1982(9), p287-300.

[3] AAKER J. Dimensions of brand personality. Journal of Marketing Research, 1997(8), p347356.

[4] Hayes, J. B. Antecedents and consequences of brand personality. Dissertation Abstracts International Section A: Humanities and Social Science, 2000(61), p268.

[5] Pragya Mathur, et al, Consumers' implicit theories about personality influence their brand 
personality judgments, Journal of consumer psycholoy, 2012.

[6] Goldsmith Ronald E, Flynn Leisa R, Daekwan Kim. Status Consumption and price sensitivity. Journal of Marketing Theory and Practice, 2010, 18(4), p323-338. 